\title{
Review Article \\ Danger Signals in the Initiation of the Inflammatory Response after Myocardial Infarction
}

\author{
J. J. de Haan, M. B. Smeets, G. Pasterkamp, and F. Arslan \\ Experimental Cardiology Laboratory, University Medical Center Utrecht, Heidelberglaan 100, Room G02.523, \\ 3584 CX Utrecht, The Netherlands \\ Correspondence should be addressed to J. J. de Haan; j.j.dehaan-4@umcutrecht.nl
}

Received 4 October 2013; Accepted 4 November 2013

Academic Editor: Stefan Frantz

Copyright (C) 2013 J. J. de Haan et al. This is an open access article distributed under the Creative Commons Attribution License, which permits unrestricted use, distribution, and reproduction in any medium, provided the original work is properly cited.

During myocardial infarction, sterile inflammation occurs. The danger model is a solid theoretic framework that explains this inflammation as danger associated molecular patterns activate the immune system. The innate immune system can sense danger signals through different pathogen recognition receptors (PRR) such as toll-like receptors, nod-like receptors and receptors for advanced glycation endproducts. Activation of a PRR results in the production of cytokines and the recruitment of leukocytes to the site of injury. Due to tissue damage and necrosis of cardiac cells, danger signals such as extracellular matrix (ECM) breakdown products, mitochondrial DNA, heat shock proteins and high mobility box 1 are released. Matricellular proteins are non-structural proteins expressed in the ECM and are upregulated upon injury. Some members of the matricellular protein family (like tenascin$\mathrm{C}$, osteopontin, $\mathrm{CCN} 1$ and the galectins) have been implicated in the inflammatory and reparative responses following myocardial infarction and may function as danger signals. In a clinical setting, danger signals can function as prognostic and/or diagnostic biomarkers and for drug targeting. In this review we will provide an overview of the established knowledge on the role of danger signals in myocardial infarction and we will discuss areas of interest for future research.

\section{Introduction}

In 1994, Matzinger postulated a theory that the immune system may not be evolved to distinguish between self and nonself, but rather sense "danger" [1]. Danger signals, besides pathogen associated molecular patterns (PAMPs), can be intracellular molecules that are normally not exposed to the immune system, for example, cardiac myosin and mitochondrial DNA, but also proteins that are only upregulated during injury, such as heat shock proteins (HSP). Danger signals can therefore be divided into constitutive and inducible. Furthermore, danger signals can be classified as truly primal initiators, which do not require previous activation of antigen presenting cells (APC) or positive feedback signals, which can amplify or convert an ongoing inflammatory response [2]. This danger model explains the inflammatory response following myocardial infarction (MI), a situation where danger associated molecular patterns (DAMPs), and not pathogens, activate the immune system. For instance, extracellular matrix breakdown products released by the damaged myocardium and constituents of dying cardiomyocytes serve as danger signals in the infarcted myocardium, activating an inflammatory reaction. A certain amount of inflammation is required for proper healing and scar formation of the damaged myocardium. However, a prolonged presence of active leukocytes can be deleterious for the injured heart and can ultimately result in heart failure.

In the last decades we gained a lot of knowledge about danger signals, their receptors, and signaling pathways in different disease models. Also the inflammatory reaction in the heart is intensively studied and many DAMPs and their signaling pathways have been elucidated. Nevertheless, the precise actions of certain DAMPs in the heart remain unknown. In this review we will shortly address the concept of the danger model with its modulators and receptors. Subsequently, we summarize the current knowledge on danger 
signals after MI and discuss potential therapeutic possibilities and clinical applications.

\section{Sensing Danger}

The primary mechanism by which the innate immune system can detect the presence of DAMPs is via pattern recognition receptors (PRRs). Ligands for these PRRs include molecules released by dying cells such as high mobility box 1 (HMGB1) and HSPs but also self-DNA and RNA and different extracellular matrix components. There are different classes of PRRs which sometimes share the same ligand and signaling pathways. In this review we will mainly focus on the membrane-bound Toll-Like Receptors (TLRs), the intracellular nucleotide binding and oligomerization domain (NOD)-like receptors (NLRs), and the Receptor for Advanced Glycation End-Products (RAGE). Both TLR and NLR can be activated through either PAMPs or DAMPs. Interaction with coreceptors like CD24-Siglec-G/-10 [3] or CD14/MD2 [4] allows the PRRs to discriminate between DAMPs and PAMPs and subsequently influence the level of inflammation [5]. In general, activation of PRRs results in the production of proinflammatory cytokines and recruitment and activation of immune cells (Figure 1).

2.1. Toll-Like Receptors. TLR is one of the best-described PRRs families. They are transmembrane receptors that can be divided into two groups, based on ligands and subcellular location. TLR1, TLR2, TLR4, TLR5, TLR6, TLR10, and TLR11 are located on the cell surface and scan the extracellular environment. TLR3, TLR7, TLR8, and TLR9 are present on the membrane of endosomal compartments of the cell and responsible for the recognition of, for example, microbial nucleic acids or self-DNA/RNA from dying cells.

TLR activation results in dimerization of the cytoplasmic signaling domains of TLRs. This subsequently initiates an intracellular signaling pathway involving specific adaptor molecules like MyD88 or TRIF. The MyD88 pathway can be used by all TLRs except TLR3 [6] and results in a cumulative activation of NF- $\kappa$ B that mediates the transcription of proinflammatory cytokines. The TRIF pathway, independent of MyD88, can be activated via TLR3 and TLR4 [7] and results in the synthesis of interferon (IFN) (Figure 1).

The first article demonstrating an interaction between TLR and DAMPs was in 2000 by Ohashi who demonstrated that HSP60 could bind to and activate TLR4 [8]. Since then, the list of DAMPs that can activate TLRs is expanding rapidly. Depending on their biological background, TLRs can be activated by different types of DAMPs (Table 1).

In cardiac ischemic injury the role of TLRs has been intensively investigated $[9,10]$ and been linked to noninfectious tissue injury. TLR2 and TLR4 are the most extensively studied receptors in myocardial ischemic injury. TLR2 knockout $(\mathrm{KO})$ mice have a reduced infarct size, improved cardiac function, and attenuated myocardial inflammation which is mediated via leucocytic TLR2 expression [11, 12]. Inhibition of TLR2 via an anti-TLR2 antibody also reduces infarct size and preserves cardiac function [13, 14]. In addition, TLR4 has a proinflammatory function during myocardial injury. TLR4 KO mice show reduced infarct sizes, attenuated adverse remodeling, and decreased inflammation $[15,16]$.

2.2. NOD-Like Receptors. NLRs are a class of intracellular receptors that recognize a variety of PAMPs and DAMPs and are highly conserved between species. So far, 22 different members have been identified in human, though the function of many remains unknown. All NLRs share the central nucleotide-binding and oligomerization (NACHT) domain, which is flanked by C-terminal leucine-rich repeats (LRRs) and N-terminal caspase recruitment (CARD) or pyrin (PYD) domains. Based on phylogenetic studies and similarities on domain structures, the NLR family can be divided into 3 subfamilies: the NODs, the NLRPs, and the IPAF.

The best known members of the NOD family are NOD1 and NOD2. Both initiate proinflammatory signaling via mitogen-activated protein kinase (MAPK) and NF- $\kappa$ B pathways $[17,18]$. There are many studies demonstrating a role for NOD1 and NOD2 in the recognition of peptidoglycan. However, there is still no evidence for direct binding to their ligands. In contrast to other NLRs, no endogenous ligands have been described for NOD1 and NOD2 so far.

Many of the IPAF and NLR subfamily members are well known for their capability to form large multiprotein complexes called inflammasomes that control caspase-1 activity. These include IPAF (or NLRC4) and NAIP (or NLRB1) from the IPAF subfamily and NLRP1, NLRP3, IPAF, and AIM2 from the NLRP family. Activation of the inflammasome involves a signaling complex consisting of a NLR protein, the adaptor ASC (apoptotic speck-containing protein with a CARD), and procaspase- 1 and finally results in the formation of the pro-inflammatory cytokines IL-1 $\beta$ and IL-18 (Figure 1). For a more detailed description of inflammasome function, we refer to excellent review articles from Latz and Schroder $[66,67]$. Notable, the important role of inflammasomes in myocardial ischemic injury has been described in several studies [68-70]. There are many different endogenous ligands that can activate inflammasomes (Table 1). For example, the AIM2 inflammasome can sense cytoplasmic DNA [56, 71] and the NLRP3 inflammasome can be activated via C3a [72], extracellular acidosis [73], and extracellular $\mathrm{Ca}^{2+}$ [74].

Although they have not been studied as extensively as TLR, there are a number of studies that demonstrate a role for NLR in myocardial ischemic injury. Already in 2001, it was demonstrated that caspase-1 inhibition reduces myocardial ischemia injury [75], whereas activation of NOD1 induces cardiac dysfunction and modulates cardiac fibrosis and cardiomyocyte apoptosis [76]. More recently, studies with KO mice demonstrate the direct role of NLR in myocardial ischemic injury. NLRP3 KO mice show improved cardiac function and decreased infarct size [69]. Similar results are found using either ASC or caspase-1 KO mice [68].

2.3. Receptor for Advanced Glycation End-Products. RAGE is the only AGE receptor that has been implied to play a role in DAMP recognition. It is a membrane bound multiligand 


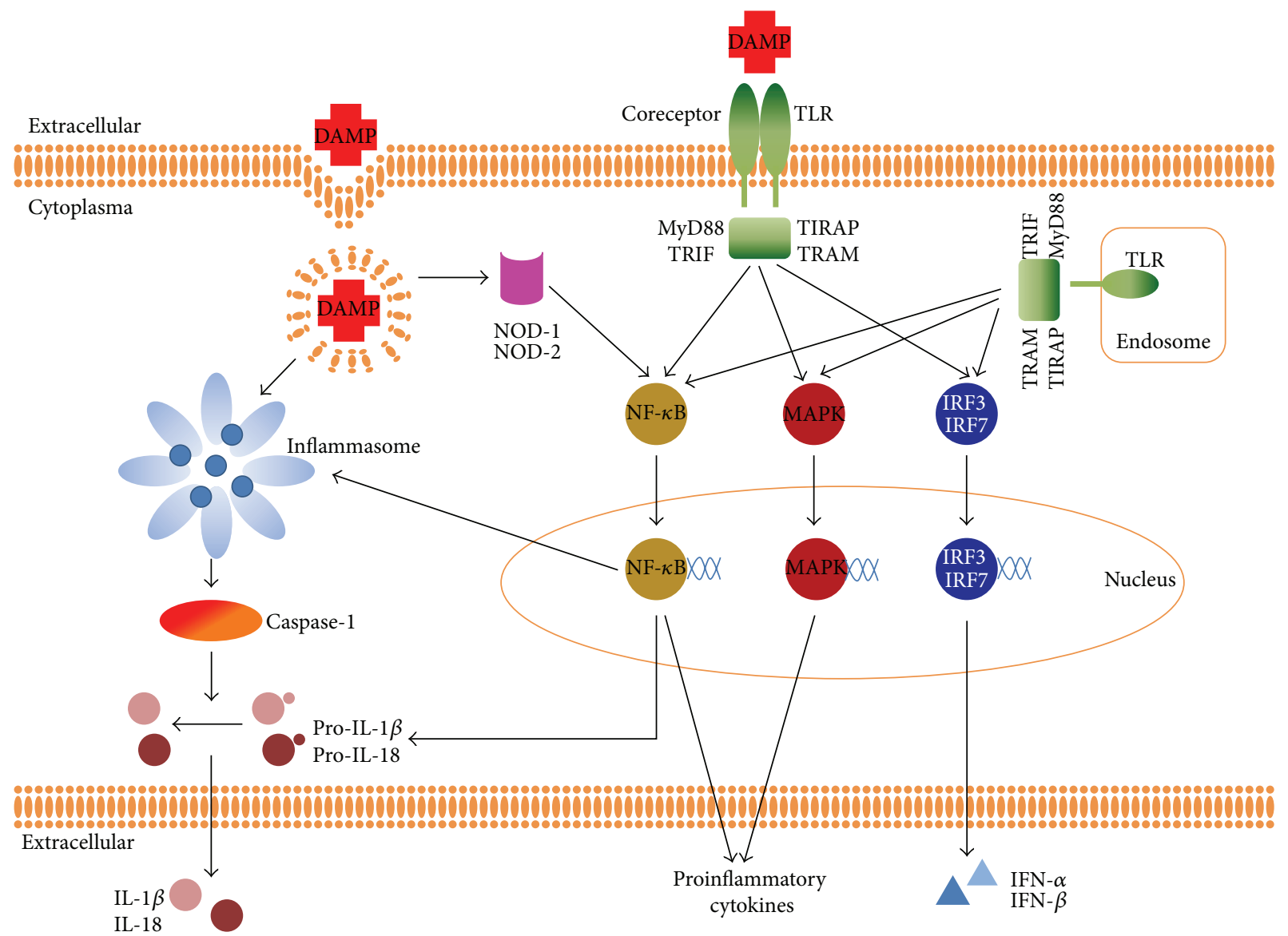

FIGURE 1: DAMP signaling through different PRRs. TLR activation by DAMPS triggers adaptor proteins MyD88, TRIF, TIRAP, or TRAM to activate various transcriptions factors. The subsequent translocation of NF- $\kappa$ B and MAPK leads to the production of several proinflammatory cytokines. TRIF-dependent activation of transcription factors IRF3 and IRF7 results in the induction of type I interferon. Additionally, the TLR- NF- $\kappa$ B pathway can induce the transcription of pro-IL-1 $\beta$, pro-IL-18, and other components of the inflammasome pathway. Inflammasome activation is considered to depend on two distinct signals. The first signal via TLR and this might be the rate limiting step for inflammasome assembly and activity; the second signal via NLR which is responsible for inflammasome assembly, caspase-1 activation, and secretion of IL- $1 \beta$ and IL-18. Activation of NOD receptors results in activation of the NF- $\kappa$ B pathway.

receptor that can recognize, besides AGE, multiple ligands including HMGB1, amphoterin, and several S100 proteins $[77,78]$. Recently, several secreted isoforms of RAGE have been described that lack the transmembrane domain and the cytosolic tail which might act as a "decoy" receptor [79-81].

RAGE signaling appears to be detrimental after MI, since recombinant HMGB1 or recombinant S100A8/A9 worsened ischemia-/reperfusion injury. Furthermore, RAGE KO mice show reduced tissue damage and less inflammation after MI $[40,82]$.

2.4. Synergy and Cross-Talk. There is a high level of interplay between the different PRRs family members and they also share several common ligands like HMGB1, S100A8/A9 complex, and $\beta$-sheet fibrils $[40,41,53,54,83]$. It is generally accepted that IL-1 $\beta$ release by the inflammasome requires two distinct signals where the first signal primes the cell via TLR. As most cells do not constitutively express high amounts of pro-IL-1 $\beta$, TLR activation and subsequent NF- $\kappa$ B translocation to the nucleus results in increased expression of pro-IL- $1 \beta$, pro-IL-18, and other inflammatory components like NLRP3 [69, 84-86]; the secondary (endogenous) stimulus then promotes inflammasome assembly, activation, and subsequent secretion of IL-1 $\beta$ and IL-18. The necessity of costimulation via two receptor types might function as a failsafe mechanism to make sure that only in the presence of a real stimulus such as tissue injury, the activation of the proinflammatory pathways occurs.

Another example of the interaction between different PRRs family members is demonstrated after costimulation of both TLR2 and NOD1 [87] which result in enhanced proliferation, expansion, and effector function of $\mathrm{T}$ cells. In contrast, costimulation with TLR2 and NOD2 is responsible for an augmented inflammatory response [88]. Interestingly, there can also be a negative regulation when TLR2 and NOD2 are simultaneously activated, NOD2 has also been described to play a suppressive function in TLR2 signaling [89].

There is also evidence that endogenous ligands can interact with each other to enhance or dampen the inflammatory 
TABLE 1: DAMPs and their receptors.

\begin{tabular}{|c|c|c|c|c|c|}
\hline & Endogenous ligand & TLR & NLR & Others & References \\
\hline \multirow{14}{*}{ Proteins, peptides } & Amyloid- $\beta$ & TRL2, TLR4/6 & NLRP3 & & {$[19-21]$} \\
\hline & $\begin{array}{l}\text { Complement membrane } \\
\text { attack complex }\end{array}$ & & NLRP3 & & {$[22]$} \\
\hline & $\alpha$ and $\beta$ defensins & TLR4 & NLRP3 & & {$[23,24]$} \\
\hline & $\begin{array}{l}\text { Eosinophil-derived } \\
\text { neurotoxin }\end{array}$ & TLR2 & & & {$[25]$} \\
\hline & Fetuin A & TLR4 & & & {$[26]$} \\
\hline & Fibrinogen & TLR4 & & & [27] \\
\hline & Fibronectin-EDA & TLR2, TLR4 & & & {$[11,28-30]$} \\
\hline & HMGB1 & TLR2, TLR4, and TLR9 & & RAGE & {$[31-34]$} \\
\hline & HSP60 & TLR2, TLR4 & & & {$[35-37]$} \\
\hline & HSP70 & TRL2, TLR4/6 & & & {$[38]$} \\
\hline & Osteopontin & TLR9 (MyD88) & & & [39] \\
\hline & S100A8/A9 & TLR4 & NLRP3 & RAGE & {$[40-42]$} \\
\hline & Tenascin-C & TLR4 & & & {$[43]$} \\
\hline & TNF- $\alpha$ & NLRP3 & & & {$[44]$} \\
\hline \multirow{3}{*}{$\begin{array}{l}\text { Proteoglycans, } \\
\text { Glycosaminoglycans }\end{array}$} & Biglycan & TLR2, TLR4 & NLRP3 & & {$[45,46]$} \\
\hline & Hyaluronic acid fragments & TLR2, TLR4 & & & {$[47,48]$} \\
\hline & Versican & TLR2/6 & & & {$[49]$} \\
\hline \multirow{4}{*}{ Fatty acids, lipoproteins } & Cholesterol crystals & & NLRP3 & & {$[50]$} \\
\hline & Oxidized LDL & TLR2,TLR4, and TLR4/6 & & & {$[20,51]$} \\
\hline & Saturated fatty acids & TLR4 & & & {$[52]$} \\
\hline & Serum amyloid A & TLR2, TLR4 & NLRP3 & & [53-55] \\
\hline \multirow{3}{*}{ Nucleic acids } & Mitochondrial DNA & TLR9 & AIM2, NLRP3 & & {$[54,56,57]$} \\
\hline & mRNA & TLR3 & & & {$[58]$} \\
\hline & ss RNA & TLR7, TLR8 & & & {$[59]$} \\
\hline \multirow{2}{*}{$\begin{array}{l}\text { Protein-nucleotide } \\
\text { complexes }\end{array}$} & IgG-chromatin complexes & TLR9 & & & {$[60]$} \\
\hline & $\begin{array}{l}\text { HMGB1-nucleosome } \\
\text { complex }\end{array}$ & TLR2 & & & {$[61]$} \\
\hline \multirow{2}{*}{ Purine metabolites } & ATP & & NLRP1b, NLRP3 & & {$[62,63]$} \\
\hline & Uric acid & TLR2, TLR4 & NLRP3 & & {$[64,65]$} \\
\hline
\end{tabular}

response that they elicit. A classic example is HMGB1 that was first identified as a DAMP. However, several studies demonstrated recently that the formation of complexes with other proinflammatory ligands results in enhanced inflammation instead of HMGB1 alone [90]. For example, HMGB1 can facilitate the transfer of LPS to CD14 [91] and enhances nucleosome binding to TLR2 [61] and dsDNA binding to TLR9 [92].

\section{High Mobility Box 1}

High mobility box 1 (HMGB1, also known as HMG1, amphoterin, or p30) was discovered as a nonhistone DNA binding protein, involved in stabilization of DNA and promotion of gene transcription. Recent discoveries established the inflammatory role of HMGB1. Scaffidi et al. demonstrated that necrotic cells release HMGB1 and hereby elicit inflammation. On the other hand during apoptosis HMGB1 is firmly attached to the chromatin, thus preventing its release and subsequent immune responses [34]. HMGB1 exhibit specific danger signal functions, because it is only released by damaged cells and activates immune responses.

HMGB1 signals through RAGE, TLR2, and TLR4, thereby stimulating macrophages, monocytes, and neutrophils to secrete the proinflammatory cytokines TNF- $\alpha$, IL-1, IL- 6 , IL-8, and macrophage inflammatory protein (MIP) [31-34]. Furthermore, HMGB1 induces the expression of adhesion molecules, for example, intercellular adhesion molecule 1 (ICAM-1) and vascular adhesion molecule 1 (VCAM-1) on endothelial cells. HMGB1 has been studied as an inflammatory mediator in a range of diseases, such as ischemia in the liver [93] and brain [94]. Also after MI there is an immediate increase of plasma HMGB1 levels in rat and 
human $[95,96]$. In the infarcted myocardium of rodents the expression of HMGB1 is upregulated after 2 [82] or 3 days [95] depending on the model used. Furthermore, the elevated levels of HMGB1 in patients with acute coronary syndrome $[95,96]$ are associated with a decreased heart rate recovery, a marker of autonomic function defined as the fall in heart rate during the first minutes of exercise [97], and adverse LV remodeling [98] and predict secondary events, such as pump failure and cardiac rupture [95]. This might reflect that increased amounts of HMGB1 are detrimental. Surprisingly, injection of HMGB1 in rat hearts after permanent coronary ligation improved cardiac function by modulating inflammation via reducing the accumulation of dendritic cells [99] and HMGB1 delivered to the heart by a hydrogel induced vascularization and improved cardiac function [100]. Furthermore, treatment of anti-HMGB1 showed enhanced adverse LV remodeling, although it prevented the upregulation of the cytokines TNF $\alpha$ and IL-1 $\beta$ and the influx of macrophages [95]. In addition, in a mouse model of permanent coronary ligation, local injection of exogenous HMGB1 improved myocardial function [101] and in transgenic mice overexpressing HMGB1 survival and cardiac function was improved after MI [102]. However, there are also studies showing opposite effects. For example, Andrassy et al. demonstrated that systemic injection of an antagonist of HMGB1 improves cardiac function after ischemia-reperfusion in WT mice and recombinant HMGB1 worsened cardiac function. Both the antagonist or the recombinant protein had no effect on RACE KO mice, which suggest that HMGB1 signaling through RAGE inhibits the reparative response after MI. Also, administration of ethyl pyruvate, which inhibits the release of HMGB1, preserves cardiac function after extended myocardial ischemia followed by reperfusion [103]. Interestingly, preconditioning with HMGB1 shows protection against ischemia-reperfusion injury [104].

These contradictory results can partly be explained by the different models that are used. In permanent coronary ligation models angiogenesis is a prominent mediator of cardiac remodeling and improves cardiac repair. HMGB1 appears to have beneficial effects in this model, which can be assigned to the role of HMGB1 in angiogenesis [102]. The detrimental effects of HMGB1 are observed in ischemiareperfusion models, in which inflammation plays a great role and might be aggravated by HMGB1. However, the amount of leukocytes is comparable in early time points after permanent ligation or reperfusion injury [105]. Thus in some cases the improved cardiac function in the different models may be explained by the route and time point of administration. Local injection after MI with HMGB1 improved cardiac function and in contrast systemic HMGB1 just before MI worsened cardiac function. Furthermore, low dose HMGB1 seems to be beneficial and high dose of HMGB1 to be harmful [106]. Apart from the great knowledge we already have about the role of HMGB1 as a danger signal, further research is required to solve the disagreement whether HMGB1 is deleterious or beneficial in ischemic heart diseases and how this can be implemented in the clinic. It should be taken into account that ischemia-reperfusion models are more clinically relevant, since all patients undergo reperfusion therapy (either pharmacologically or mechanically) in the setting of acute MI.

\section{Heat Shock Protein 60 and 70}

HSPs gain their name because their expression is upregulated as a result of high temperatures. Later it became clear that various kinds of stress responses can enhance the expression and release of HSPs. During homeostasis HSPs are expressed by numerous cell types and function as chaperones in protein folding and translocation; however, upon injury HSPs can function as danger signals. For instance, in rats, HSP27, HSP72, and HSP60 were significantly induced following coronary artery ligation, whereby the expression of HSP60 was correlated with the development of heart failure [107, 108]. In human, HSP27 and HSP60 expressions are increased in the myocardium of patients with ischemic cardiomyopathy [109] and circulating HSP70 levels are increased after acute MI $[38,110,111]$. HSP60 and HSP70 are widely studied as danger signals after MI. Endogenous and exogenous HSP60 signals via TLR4-MyD88-p38/NF- $\kappa$ B in cardiomyocytes and augments pro-inflammatory cytokine production, such as IL- $1 \beta$, TNF- $\alpha$, and IL- $6[36,37]$. Furthermore, in patients with acute coronary syndrome pro-inflammatory HSP60reactive $\mathrm{CD} 4^{+} \mathrm{CD} 28^{\text {null }} \mathrm{T}$ cells are found [112], which indicates that these T cells are activated by HSP60 stimulated APC. Likewise, this suggests that HSP60 functions as a primal danger signal after acute coronary syndrome. Similarly, HSP70 is elevated after MI and related to inflammation and TLR4 signaling $[38,111]$. Moreover, HSP70 can activate monocytes through $\mathrm{CD} 14$, which results in a release of pro-inflammatory cytokines IL-1 $\beta$, TNF- $\alpha$, and IL-6 [113]. Surprisingly, rats administered with bimoclomol, which increases HSP70 levels, exhibit decreased infarct size after coronary ligation. However, bimoclomol was given before MI induction, which is not a good clinically relevant model [114]. More studies are necessary to establish the exact role of HSP70 as a danger signal and how this can be used in the clinic.

In summary, HSP60 and HSP70 are both upregulated after MI. HSP60 has a well-established role as a danger signal, while HSP70 has only been associated with inflammation. More studies are warranted to define the role of HSPs in the clinical setting.

\section{Mitochondrial DNA}

It is known that bacterial DNA has robust immune properties. The CpG sequence abundantly present on prokaryotic DNA serves as a PAMP and activates B cells, macrophages, and DCs through the intracellular TLR9 [115]. Mitochondrial mtDNA, originating from bacteria, contains the same $\mathrm{CpG}$ sequence and can thereby function as a DAMP. Zhang et al. show that traumas, for example, myocyte injury, trigger the release of mtDNA and that circulating mtDNA provokes inflammation in polymorphonuclear neutrophils [116]. Interestingly, Oka et al. show that mtDNA can also autonomously activate TLR9 by escaping from autophagy-mediated degradation and in this 
way aggravate pressure-overloaded heart failure [117]. As a response to this paper, Konstantinidis and Kitsis postulate that this pathway may be of greater importance after MI, because inflammation is more pronounced in MI compared to chronic heart failure [118]. In addition, patients suffering from MI show increased levels of circulating mtDNA [119]. Despite the lack of studies on the effects of mtDNA in ischemic heart diseases, it can be speculated that mtDNA, released by necrotic cells or escaped from autophagy, serves as a danger signal after MI.

\section{Fibronectin-EDA}

Fibronectin (FN) is a dimeric glycoprotein found in the ECM. Different isoforms exist due to alternative splicing. The FNEDA splice variant is highly expressed during embryogenesis and upregulated upon injury. FN-EDA can bind the integrins $\alpha 9 \beta 1$ and $\alpha 4 \beta 1$, thereby mediating cell adhesion [120]. Furthermore, FN-EDA can activate leukocytes through TLR2 and TLR4 in vitro [28, 29]. FN-EDA is upregulated after $\mathrm{MI}$ in mice [121] and human (unpublished data). Moreover, EDA KO mice show less inflammation, reduced monocyte recruitment, and improved cardiac function after MI [121]. In addition, in ischemic stroke, constitutive expression of FN-EDA significantly increased neutrophil and macrophage infiltration, inflammatory cytokines, and brain injury. Interestingly, treatment with a specific TLR4 inhibitor abolished these effects, which suggests that FN-EDA by signaling through TLR4 promotes inflammation and subsequent injury [30]. Although some evidence is still lacking, it can be speculated that EDA functions as an inducible danger signal after MI by attracting and activating leukocytes through TLR and/or integrin signaling.

\section{Matricellular Proteins as Danger Signals}

Matricellular proteins are nonstructural proteins expressed in the ECM and are upregulated upon injury. Many matricellular proteins are shown to be upregulated after MI and play an important role in the reparative response. An excellent review has been published about the role of matricellular proteins in the infarcted myocardium [122]. Some matricellular proteins also show characteristics of an inducible danger signal and those will be discussed here.

7.1. Tenascin-C. Tenascin-C (TN-C) is a glycoprotein mostly expressed in the ECM during development [122] and is normally not abundantly expressed in adult tissue. TN$\mathrm{C}$ is upregulated under pathological conditions, such as pulmonary fibrosis [123] and MI [124-127] and is closely associated with inflammation [123]. Despite the fact that TN-C is upregulated in inflammatory diseases, not much is known yet about its role in vivo and whether $\mathrm{TN}-\mathrm{C}$ functions as a primal danger signal. In vitro, TN-C supports lymphocyte tethering and rolling under flow conditions [128, 129], and soluble TN-C has also been shown to inhibit $\mathrm{T}$ cell activation and proliferation $[129,130]$ through the $\alpha 5 \beta 1$ integrin [131]. In a model of rheumatoid arthritis,
TN-C shows to signal through TLR4, thereby increasing inflammation [43]. Moreover, human macrophages secrete more of the proinflammatory cytokines IL-6, IL-8, and TNF upon TN-C stimulation through TLR4 [43].

TN-C KO mice show no cardiac dysfunction in the absence of injury, suggesting that TN-C does not play a significant role in homeostasis of the heart. However, TN-C KO mice show less fibrosis and remodeling after MI. Unfortunately, in this study the inflammatory actions of TN-C were not studied. Future research should focus on the immune modulatory actions of TN-C in the infarcted myocardium to investigate whether TN-C might be an interesting candidate in controlling the inflammatory response.

7.2. Osteopontin. Osteopontin (OPN or Eta-1) was originally identified as a bone matrix protein. Later it became clear that OPN is also a cytokine, secreted by many immune cells. OPN is constitutively expressed by macrophages [132] and is upregulated in numerous cells types upon injury [133]. In macrophages OPN has been shown to function in the migration [134], activation [135], phagocytosis [133], and inflammatory cytokine production $[133,136]$. Furthermore, OPN acts as a chemoattractant for neutrophils and DCs $[136,137]$. Interestingly, OPN can activate DCs to produce IL12 and TNF- $\alpha$, which suggest that OPN functions as a primal danger signal. Additionally, OPN activated DCs stimulate a Th1 response when cocultured with naïve T cells [138-140].

OPN is upregulated in experimental models of infarction in mice [141, 142], rats [143], dogs [142], pigs [144], and in human patients suffering an acute MI $[132,145]$. OPN KO mice show excessive dilation and reduced collagen deposition of the LV upon MI [141]. Unfortunately, the mechanisms behind the decreased collagen deposition and the role of inflammatory cells are not studied, so whether OPN functions as a danger signal in MI cannot yet be defined. In patients, OPN levels are increased after MI [145] and are predictive for long-term outcome. Furthermore, their role as an immune modulator has been established in many other diseases $[133,137,146]$, so it can be speculated that OPN functions as a danger signal. However, more research is required to unravel the role and function of OPN in cardiac ischemic injury and subsequent repair, as this might lead to new therapeutic options.

7.3. CCN1. The CCN family obtained its name from the first members described, cysteine-rich protein 61(CYR61), connective tissue growth factor and nephroblastoma overexpressed protein. CCN are considered as matricellular proteins and have been shown to be involved in many cellular processes such as adhesion, migration, and proliferation, mainly via modulating signaling of other molecules [122]. CCN1, also known as CYR61, is highly upregulated in the infarcted myocardium in mice $[147,148]$ and human [148]. Furthermore, CCN2 and CCN4 are upregulated after $\mathrm{MI}$, but little is known about their inflammatory actions. Interestingly, CCN1 can activate proinflammatory genes in macrophages by binding to $\alpha_{\mathrm{M}} \beta_{2}$ and syndecan-4 [149]. However, CCN1 inhibits the migration of macrophages and 


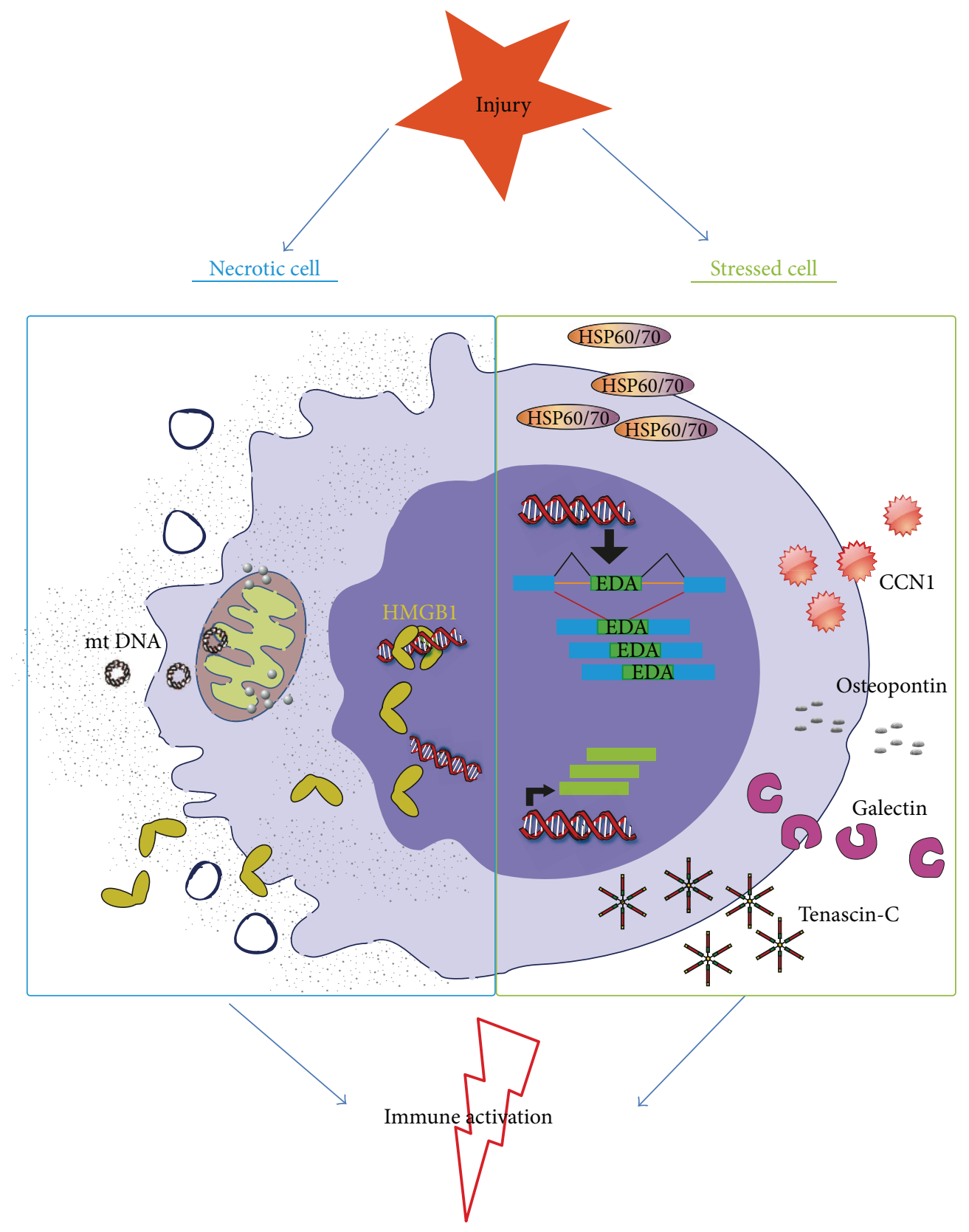

Figure 2: Proposed simplified mediators of danger signal release during myocardial infarction. Necrotic cells in the myocardium are leaky and release a subset of DAMPs, for instance, mtDNA and the DNA binding protein HMGB1. Furthermore, viable cells get stress signals from their surroundings and start to produce and secrete a range of proteins. These cells start the production of the EDA splice variant of fibronectin, HSPs and the matricellular proteins CCN1, osteopontin, galectins, and tenascin-C. Both the proteins released by necrotic cells and the produced proteins by stressed cells are able to activate or aggravate the immune response in the heart following MI.

lymphocytes in autoimmune myocarditis [150]. To explain the paradoxical role of CCN1, Löbel and colleagues showed a diphasic immune modulator response for CCN1; initial stimulation with CCN1 attracts and activates leukocytes; however, prolonged CCN1 stimulation and enhanced secretion of CCN1 by leukocytes immobilize systemic leukocytes [151]. It can be speculated that CCN1 may function as a danger signal after MI by attracting and activating leukocytes, however, in vivo studies are necessary to state this.
7.4. Galectins. Galectins are a family of proteins that have an affinity for binding $\beta$-galactosides sugars. So far, 15 different galectins have been described. Some galectins have been characterized as matricellular proteins [152], including galectin-1 and galectin-3. Both galectins have been shown to function as a DAMP [153] and found to be upregulated after MI in human $[154,155]$ and mice [155]. Galectin-3 can support neutrophil adhesion, migration, and activation. Furthermore, galectin-3 functions as a chemoattractant for 
macrophages [156] and both galectin-1 and galectin-3 can alternatively activate macrophages. Importantly, galectin-1 is able to augment DC migration, and induce maturation [157]. Interestingly, Seropian and colleagues recently showed that galectin-1 prevents cardiac inflammation in a mouse model of acute MI [155]. These studies might suggest that different galectins have distinct functions in inflammation. Not many in vivo studies have been conducted yet to establish the role of galectins as a DAMP following MI. However, it can be hypothesized that both galectin-1 and galectin-3 play a role in the inflammatory reaction.

\section{Clinical Implications}

In the clinical context, understanding the role of danger signals could have important applications. Hypothetically, all danger signals that can be measured in blood may serve as biomarkers for diagnostic and/or prognostic purposes. For example, high plasma levels of HMGB1 are shown to be strongly associated with increased mortality in patients with STEMI independent of age, sex, troponin I, and CK$\mathrm{MB}$ [158]. In addition, in patients with unstable angina or NSTEMI, high serum levels of HBGB1 are associated with higher mortality during 49 month followup [159]. Both of these studies demonstrate that HMGB1 levels can be used as a new prognostic biomarker in patients with acute coronary syndrome.

Also HSP70 might be a new biomarker for patients with heart failure. HSP70 is elevated in AMI patients and after 14 days HSP70 levels were higher in patients with heart failure compared to patients without heart failure [38]. In addition, Li et al. showed that elevated levels of HSP70 correlate with the progression of HF [110].

In critically ill patients, high levels of FN-EDA correlate with increased risk for progression to acute hypoxemic respiratory failure [160]. It would be interesting to study the prognostic value of FN-EDA levels in patients with acute coronary syndrome.

On a theoretical basis, danger signals are excellent therapeutic targets because they are only released or upregulated after injury. Nevertheless, DAMP-induced inflammation is also essential for proper healing of the infarcted area. Hence, it is of utmost importance to establish the exact time frame in which intervention is optimal. Injection of HMGB1 or an antibody against HMGB1 has extensively been studied in animal models. However, no uniform effects were observed. In some models HMGB1 seems to prevent cardiac remodeling, however, in other models HMGB1 appears to be detrimental. This is probably due to the two different MI models used to study cardiac remodeling: the permanent coronary ligation and ischemia-reperfusion. Before HMGB1 or anti-HMGB1 can be brought to the clinic, it is crucial that the mechanism of action and the therapeutic window are established. In addition to targeting a DAMP for therapeutic intervention, it is also an option to target receptors. It is challenging to inhibit a certain receptor in order to prevent DAMPPRRs interaction, since the same PRRs are necessary for host defense. Nevertheless, a few examples can be given. An
anti-TLR2 antibody reduced leukocyte influx and infarct size after MI in both mice and pigs [13]. Furthermore in a brain ischemic-reperfusion model a TLR4 inhibitor reduced injury [30] and because many DAMPs signal through TLR4 this is also an interesting candidate for the treatment of MI.

\section{Concluding Remarks}

The danger model has shown to be useful as a theoretical framework in cardiovascular science. Interesting new DAMPs are identified that might influence the deleterious and beneficial effects of the immune system in tissue healing and scar formation. Figure 2 shows how and which danger signals can be released following MI. However, for only a few danger signals a true causal relationship has been established in MI and for many danger signals research is still ongoing to establish their effects in MI. It will be interesting to use conditional $\mathrm{KO}$ and bone marrow chimera approaches to investigate which cells release and produce the danger signal of interest. Furthermore, ECM breakdown products and matricellular proteins are of main interest to study as potential danger signals. Danger signals, or DAMPs, may also be used as diagnostic and prognostic markers. Additional studies on correlation between specific danger signals and primary and/or secondary outcome are necessary before clinical application. Intracellular and inducible DAMPs, such as mtDNA and matricellular proteins, are interesting candidates for therapeutic interventions, considering that they are only present in the injured environment.

To conclude, extended research is necessary to define the role of specific danger signals in MI. Regardless, DAMPs may be of additive value in the clinic as diagnostic/prognostic markers and therapeutic targets.

\section{Conflict of Interests}

The author declare that they have no conflict of interests.

\section{References}

[1] P. Matzinger, "Tolerance, danger, and the extended family," Annual Review of Immunology, vol. 12, pp. 991-1045, 1994.

[2] S. Gallucci and P. Matzinger, "Danger signals: SOS to the immune system," Current Opinion in Immunology, vol. 13, no. 1, pp. 114-119, 2001.

[3] G.-Y. Chen, J. Tang, P. Zheng, and Y. Liu, "CD24 and siglec-10 selectively repress tissue damage-induced immune responses," Science, vol. 323, no. 5922, pp. 1722-1725, 2009.

[4] K.-H. Chun and S.-Y. Seong, "CD14 but not MD2 transmit signals from DAMP," International Immunopharmacology, vol. 10, no. 1, pp. 98-106, 2010.

[5] K. S. Midwood and A. M. Piccinini, "DAMPening inflammation by modulating TLR signalling," Mediators of Inflammation, vol. 2010, Article ID 672395, 21 pages, 2010.

[6] T. Kawai and S. Akira, "The role of pattern-recognition receptors in innate immunity: update on toll-like receptors," Nature Immunology, vol. 11, no. 5, pp. 373-384, 2010. 
[7] M. Yamamoto, S. Sato, H. Hemmi et al., "Role of adaptor TRIF in the MyD88-independent toll-like receptor signaling pathway," Science, vol. 301, no. 5633, pp. 640-643, 2003.

[8] K. Ohashi, V. Burkart, S. Flohé, and H. Kolb, "Cutting edge: heat shock protein 60 is a putative endogenous ligand of the toll-like receptor-4 complex," The Journal of Immunology, vol. 164, no. 2 , pp. 558-561, 2000.

[9] W. Chao, "Toll-like receptor signaling: a critical modulator of cell survival and ischemic injury in the heart," The American Journal of Physiology: Heart and Circulatory Physiology, vol. 296, no. 1, pp. H1-H12, 2009.

[10] Y. Feng and W. Chao, "Toll-like receptors and myocardial inflammation," International Journal of Inflammation, vol. 2011, Article ID 170352, 21 pages, 2011.

[11] F. Arslan, M. B. Smeets, L. A. J. O’Neill et al., "Myocardial ischemia/reperfusion injury is mediated by leukocytic toll-like receptor- 2 and reduced by systemic administration of a novel anti-toll-like receptor-2 antibody," Circulation, vol. 121, no. 1, pp. 80-90, 2010.

[12] J. Favre, P. Musette, V. Douin-Echinard et al., "Toll-like receptors 2-deficient mice are protected against postischemic coronary endothelial dysfunction," Arteriosclerosis, Thrombosis, and Vascular Biology, vol. 27, no. 5, pp. 1064-1071, 2007.

[13] F. Arslan, J. H. Houtgraaf, B. Keogh et al., "Treatment with OPN-305, a humanized anti-Toll-Like receptor-2 antibody, reduces myocardial ischemia/reperfusion injury in pigs," Circulation, vol. 5, pp. 279-287, 2012.

[14] H.-S. Ding, J. Yang, P. Chen et al., "The HMGB1-TLR4 axis contributes to myocardial ischemia/reperfusion injury via regulation of cardiomyocyte apoptosis," Gene, vol. 527, no. 1, pp. 389-393, 2013.

[15] J.-I. Oyama, C. Blais Jr., X. Liu et al., "Reduced myocardial ischemia-reperfusion injury in Toll-like receptor 4-deficient mice," Circulation, vol. 109, no. 6, pp. 784-789, 2004.

[16] L. Timmers, J. P. G. Sluijter, J. K. van Keulen et al., “Toll-like receptor 4 mediates maladaptive left ventricular remodeling and impairs cardiac function after myocardial infarction," Circulation Research, vol. 102, no. 2, pp. 257-264, 2008.

[17] N. Inohara, T. Koseki, L. del Peso et al., "Nod1, an Apaf-1-like activator of caspase- 9 and nuclear factor- $\kappa \mathrm{B}$," The Journal of Biological Chemistry, vol. 274, no. 21, pp. 14560-14567, 1999.

[18] Y. Ogura, N. Inohara, A. Benito, F. F. Chen, S. Yamaoka, and G. Núñez, "Nod2, a Nod1/Apaf-1 Family Member That Is Restricted to Monocytes and Activates NF- $\kappa \mathrm{B}$," The Journal of Biological Chemistry, vol. 276, no. 7, pp. 4812-4818, 2001.

[19] A. Halle, V. Hornung, G. C. Petzold et al., "The NALP3 inflammasome is involved in the innate immune response to amyloid- $\beta$," Nature Immunology, vol. 9, no. 8, pp. 857-865, 2008.

[20] C. R. Stewart, L. M. Stuart, K. Wilkinson et al., "CD36 ligands promote sterile inflammation through assembly of a Toll-like receptor 4 and 6 heterodimer," Nature Immunology, vol. 11, no. 2, pp. 155-161, 2010.

[21] M. Jana, C. A. Palencia, and K. Pahan, "Fibrillar amyloid- $\beta$ peptides activate microglia via TLR2: implications for Alzheimer's disease," The Journal of Immunology, vol. 181, no. 10, pp. 72547262,2008 .

[22] F. Laudisi, R. Spreafico, M. Evrard et al., "Cutting edge: the NLRP3 inflammasome links complement-mediated inflammation and IL- $1 \beta$ release," The Journal of Immunology, vol. 191, pp. 1006-1010, 2013.
[23] D. Burzyn, J. C. Rassa, D. Kim, I. Nepomnaschy, S. R. Ross, and I. Piazzon, "Toll-like receptor 4-dependent activation of dendritic cells by a retrovirus," Journal of Virology, vol. 78, no. 2, pp. 576-584, 2004.

[24] Q. Chen, Y. Jin, K. Zhang et al., "Alarmin HNP-1 promotes pyroptosis and IL- $1 \beta$ Release through different roles of NLRP3 inflammasome via P2X7 in LPS-primed macrophages," Innate Immunity, pp. 1-11, 2013.

[25] D. Yang, Q. Chen, B. S. Shao et al., "Eosinophil-derived neurotoxin acts as an alarmin to activate the TLR2-MyD88 signal pathway in dendritic cells and enhances Th2 immune responses," Journal of Experimental Medicine, vol. 205, no. 1, pp. 79-90, 2008.

[26] D. Pal, S. Dasgupta, R. Kundu, S. Maitra et al., "Fetuin-A acts as an endogenous ligand of TLR4 to promote lipid-induced insulin resistance," Nature Medicine, vol. 18, pp. 1279-1285, 2012.

[27] S. T. Smiley, J. A. King, and W. W. Hancock, "Fibrinogen stimulates macrophage chemokine secretion through Toll-like receptor 4," The Journal of Immunology, vol. 167, no. 5, pp. 28872894, 2001.

[28] Y. Okamura, M. Watari, E. S. Jerud et al., "The extra domain A of fibronectin activates Toll-like receptor 4," The Journal of Biological Chemistry, vol. 276, no. 13, pp. 10229-10233, 2001.

[29] A. H. Schoneveld, I. Hoefer, J. P. G. Sluijter, J. D. Laman, D. P. V. de Kleijn, and G. Pasterkamp, "Atherosclerotic lesion development and Toll like receptor 2 and 4 responsiveness," Atherosclerosis, vol. 197, no. 1, pp. 95-104, 2008.

[30] M. M. Khan, C. Gandhi, N. Chauhan et al., "Alternativelyspliced extra domain a of fibronectin promotes acute inflammation and brain injury after cerebral ischemia in mice," Stroke, vol. 43, no. 5, pp. 1376-1382, 2012.

[31] J. Li, R. Kokkola, S. Tabibzadeh et al., "Structural basis for the proinflammatory cytokine activity of high mobility group box 1," Molecular Medicine, vol. 9, no. 1-2, pp. 37-45, 2003.

[32] J. S. Park, J. Arcaroli, H.-K. Yum et al., "Activation of gene expression in human neutrophils by high mobility group box 1 protein," The American Journal of Physiology: Cell Physiology, vol. 284, no. 4, pp. C870-C879, 2003.

[33] J. S. Park, D. Svetkauskaite, Q. He et al., "Involvement of Toll-like receptors 2 and 4 in cellular activation by high mobility group box 1 protein," The Journal of Biological Chemistry, vol. 279, no. 9, pp. 7370-7377, 2004.

[34] P. Scaffidi, T. Misteli, and M. E. Bianchi, "Release of chromatin protein HMGB1 by necrotic cells triggers inflammation," Nature, vol. 418, no. 191, p. 195, 2002.

[35] R. M. Vabulas, P. Ahmad-Nejad, C. Da Costa et al., "Endocytosed HSP60s use Toll-like receptor 2 (TLR2) and TLR4 to activate the Toll/Interleukin-1 receptor signaling pathway in innate immune cells," The Journal of Biological Chemistry, vol. 276, no. 33, pp. 31332-31339, 2001.

[36] Y. Li, R. Si, Y. Feng et al., "Myocardial ischemia activates an injurious innate immune signaling via cardiac heat shock protein 60 and toll-like receptor 4," The Journal of Biological Chemistry, vol. 286, no. 36, pp. 31308-31319, 2011.

[37] J. Tian, X. Guo, X. -M. Liu et al., "Extracellular HSP60 induces inflammation through activating and up-regulating TLRs in cardiomyocytes," Cardiovascular Research, vol. 98, pp. 391-401, 2013.

[38] M. Satoh, Y. Shimoda, T. Akatsu, Y. Ishikawa, Y. Minami, and M. Nakamura, "Elevated circulating levels of heat shock protein 70 are related to systemic inflammatory reaction through 
monocyte Toll signal in patients with heart failure after acute myocardial infarction," European Journal of Heart Failure, vol. 8, no. 8, pp. 810-815, 2006.

[39] M. L. Shinohara, L. Lu, J. Bu et al., "Osteopontin expression is essential for interferon- $\alpha$ production by plasmacytoid dendritic cells," Nature Immunology, vol. 7, no. 5, pp. 498-506, 2006.

[40] H. C. Volz, D. Laohachewin, C. Seidel et al., "S100A8/A9 aggravates post-ischemic heart failure through activation of RAGEdependent NF- $\kappa$ B signaling," Basic Research in Cardiology, vol. 107, no. 2, article 250, 2012.

[41] T. Vogl, K. Tenbrock, S. Ludwig et al., "Mrp8 and Mrp14 are endogenous activators of Toll-like receptor 4, promoting lethal, endotoxin-induced shock," Nature Medicine, vol. 13, no. 9, pp. 1042-1049, 2007.

[42] J.-C. Simard, A. Cesaro, J. Chapeton-Montes et al., "S100A8 and S100A9 induce cytokine expression and regulate the NLRP3 inflammasome via ROS-dependent activation of NF-kappaB (1.)," PLoS ONE, vol. 8, Article ID e72138, 2013.

[43] K. Midwood, S. Sacre, A. M. Piccinini et al., "Tenascin-C is an endogenous activator of Toll-like receptor 4 that is essential for maintaining inflammation in arthritic joint disease," Nature Medicine, vol. 15, no. 7, pp. 774-780, 2009.

[44] L. Franchi, T. Eigenbrod, and G. Núñez, "Cutting edge: TNF$\alpha$ mediates sensitization to ATP and silica via the NLRP3 inflammasome in the absence of microbial stimulation," The Journal of Immunology, vol. 183, no. 2, pp. 792-796, 2009.

[45] A. Babelova, K. Moreth, W. Tsalastra-Greul et al., "Biglycan, a danger signal that activates the NLRP3 inflammasome via tolllike and P2X receptors," The Journal of Biological Chemistry, vol. 284, no. 36, pp. 24035-24048, 2009.

[46] L. Schaefer, A. Babelova, E. Kiss et al., "The matrix component biglycan is proinflammatory and signals through Tolllike receptors 4 and 2 in macrophages," Journal of Clinical Investigation, vol. 115, no. 8, pp. 2223-2233, 2005.

[47] K. A. Scheibner, M. A. Lutz, S. Boodoo, M. J. Fenton, J. D. Powell, and M. R. Horton, "Hyaluronan fragments act as an endogenous danger signal by engaging TLR2," The Journal of Immunology, vol. 177, no. 2, pp. 1272-1281, 2006.

[48] D. Jiang, J. Liang, J. Fan et al., "Regulation of lung injury and repair by Toll-like receptors and hyaluronan," Nature Medicine, vol. 11, no. 11, pp. 1173-1179, 2005.

[49] S. Kim, H. Takahashi, W.-W. Lin et al., "Carcinoma-produced factors activate myeloid cells through TLR2 to stimulate metastasis," Nature, vol. 457, no. 7225, pp. 102-106, 2009.

[50] P. Duewell, H. Kono, K. J. Rayner et al., "NLRP3 inflammasomes are required for atherogenesis and activated by cholesterol crystals," Nature, vol. 464, no. 1357, p. 1361, 2010.

[51] Y. S. Bae, J. H. Lee, S. H. Choi et al., "Macrophages generate reactive oxygen species in response to minimally oxidized lowdensity lipoprotein: Toll-like receptor 4- and spleen tyrosine kinase-dependent activation of NADPH oxidase 2," Circulation Research, vol. 104, no. 2, pp. 210-218, 2009.

[52] J. Y. Lee, K. H. Sohn, S. H. Rhee, and D. Hwang, "Saturated fatty acids, but not unsaturated fatty acids, induce the expression of cyclooxygenase-2 mediated through Toll-like receptor 4," The Journal of Biological Chemistry, vol. 276, no. 20, pp. 1668316689, 2001.

[53] N. Cheng, R. He, J. Tian, P. P. Ye, and R. D. Ye, "Cutting edge: TLR2 is a functional receptor for acute-phase serum amyloid A," The Journal of Immunology, vol. 181, no. 1, pp. 22-26, 2008.
[54] K. Niemi, L. Teirilä, J. Lappalainen et al., "Serum amyloid A activates the NLRP3 inflammasome via P2X7 receptor and a cathepsin B-sensitive pathway," The Journal of Immunology, vol. 186, no. 11, pp. 6119-6128, 2011.

[55] S. Hiratsuka, A. Watanabe, Y. Sakurai et al., "The S100A8serum amyloid A3-TLR4 paracrine cascade establishes a premetastatic phase," Nature Cell Biology, vol. 10, no. 11, pp. 13491355, 2008.

[56] V. Hornung, A. Ablasser, M. Charrel-Dennis et al., "AIM2 recognizes cytosolic dsDNA and forms a caspase-1-activating inflammasome with ASC," Nature, vol. 458, no. 7237, pp. 514$518,2009$.

[57] R. Zhou, A. S. Yazdi, P. Menu, and J. Tschopp, "A role for mitochondria in NLRP3 inflammasome activation," Nature, vol. 469, pp. 221-225, 2011.

[58] K. Karikó, H. Ni, J. Capodici, M. Lamphier, and D. Weissman, "mRNA is an endogenous ligand for Toll-like receptor 3," The Journal of Biological Chemistry, vol. 279, no. 13, pp. 12542-12550, 2004.

[59] B. Scheel, R. Teufel, J. Probst et al., "Toll-like receptordependent activation of several human blood cell types by protamine-condensed mRNA," European Journal of Immunology, vol. 35, no. 5, pp. 1557-1566, 2005.

[60] E. A. Leadbetter, I. R. Rifkin, A. M. Hohlbaum, B. C. Beaudette, M. J. Shlomchik, and A. Marshak-Rothstein, "Chromatin-IgG complexes activate B cells by dual engagement of IgM and Tolllike receptors," Nature, vol. 416, no. 6881, pp. 603-607, 2002.

[61] V. Urbonaviciute, B. G. Fürnrohr, S. Meister et al., "Induction of inflammatory and immune responses by HMGB1-nucleosome complexes: Implications for the pathogenesis of SLE," Journal of Experimental Medicine, vol. 205, no. 13, pp. 3007-3018, 2008.

[62] S. Mariathasan, D. S. Weiss, K. Newton et al., "Cryopyrin activates the inflammasome in response to toxins and ATP," Nature, vol. 440, no. 7081, pp. 228-232, 2006.

[63] K. -C. Liao and J. Mogridge, "Activation of the Nlrplb inflammasome by reduction of cytosolic ATP," Infection and Immunity, vol. 81, pp. 570-579, 2013.

[64] R. Liu-Bryan, P. Scott, A. Sydlaske, D. M. Rose, and R. Terkeltaub, "Innate immunity conferred by Toll-like receptors 2 and 4 and myeloid differentiation factor 88 expression is pivotal to monosodium urate monohydrate crystal-induced inflammation," Arthritis \& Rheumatism, vol. 52, no. 9, pp. 29362946, 2005.

[65] F. Martinon, V. Pétrilli, A. Mayor, A. Tardivel, and J. Tschopp, "Gout-associated uric acid crystals activate the NALP3 inflammasome," Nature, vol. 440, no. 7081, pp. 237-241, 2006.

[66] E. Latz, T. S. Xiao, and A. Stutz, "Activation and regulation of the inflammasomes," Nature Reviews Immunology, vol. 13, pp. 397-411, 2013.

[67] K. Schroder and J. Tschopp, “The Inflammasomes," Cell, vol. 140, no. 6, pp. 821-832, 2010.

[68] M. Kawaguchi, M. Takahashi, T. Hata et al., "Inflammasome activation of cardiac fibroblasts is essential for myocardial ischemia/reperfusion injury," Circulation, vol. 123, no. 6, pp. 594-604, 2011.

[69] Ø. Sandanger, T. Ranheim, L. E. Vinge et al., “The NLRP3 inflammasome is up-regulated in cardiac fibroblasts and mediates myocardial ischaemia-reperfusion injury," Cardiovascular Research, vol. 99, pp. 164-174, 2013.

[70] C. J. Zuurbier, W. M. C. Jong, O. Eerbeek et al., "Deletion of the innate immune NLRP3 receptor abolishes cardiac ischemic 
preconditioning and is associated with decreased Il-6/STAT3 signaling," PLoS ONE, vol. 7, Article ID e40643, 2012.

[71] T. Fernandes-Alnemri, J.-W. Yu, P. Datta, J. Wu, and E. S. Alnemri, "AIM2 activates the inflammasome and cell death in response to cytoplasmic DNA," Nature, vol. 458, no. 7237, pp. 509-513, 2009.

[72] E. Asgari, G. Le Friec, H. Yamamoto et al., "C3a modulates IL$1 \beta$ secretion in human monocytes by regulating ATP efflux and subsequent NLRP3 inflammasome activation," Blood, vol. 122, no. 20, pp. 3473-3481, 2013.

[73] K. Rajamäki, T. Nordström, K. Nurmi et al., "Extracellular acidosis is a novel danger signal alerting innate immunity via the NLRP3 inflammasome," The Journal of Biological Chemistry, vol. 288, no. 19, pp. 13410-13419, 2013.

[74] M. Rossol, M. Pierer, N. Raulien et al., "Extracellular $\mathrm{Ca}^{2+}$ is a danger signal activating the NLRP3 inflammasome through G protein-coupled calcium sensing receptors," Nature Communications, vol. 3, pp. 1-9, 2012.

[75] B. J. Pomerantz, L. L. Reznikov, A. H. Harken, and C. A. Dinarello, "Inhibition of caspase 1 reduces human myocardial ischemic dysfunction via inhibition of IL-18 and IL-1 $\beta$," Proceedings of the National Academy of Sciences of the United States of America, vol. 98, no. 5, pp. 2871-2876, 2001.

[76] M. Fernández-Velasco, P. Prieto, V. Terrón et al., "NOD1 activation induces cardiac dysfunction and modulates cardiac fibrosis and cardiomyocyte apoptosis," PLoS ONE, vol. 7, Article ID e45260, 2012.

[77] A. Taguchi, D. C. Blood, G. del Toro et al., "Blockade of RAGE-amphoterin signalling suppresses tumour growth and metastases," Nature, vol. 405, no. 6784, pp. 354-360, 2000.

[78] M. A. Hofmann, S. Drury, C. Fu et al., "RAGE mediates a novel proinflammatory axis: a central cell surface receptor for S100/calgranulin polypeptides," Cell, vol. 97, no. 7, pp. 889-901, 1999.

[79] A. Bierhaus, P. M. Humpert, M. Morcos et al., "Understanding RAGE, the receptor for advanced glycation end products," Journal of Molecular Medicine, vol. 83, no. 11, pp. 876-886, 2005.

[80] H. Yonekura, Y. Yamamoto, S. Sakurai et al., "Novel splice variants of the receptor for advanced glycation end-products expressed in human vascular endothelial cells and pericytes, and their putative roles in diabetes-induced vascular injury," Biochemical Journal, vol. 370, no. 3, pp. 1097-1109, 2003.

[81] C. Schlueter, S. Hauke, A. M. Flohr, P. Rogalla, and J. Bullerdiek, "Tissue-specific expression patterns of the RAGE receptor and its soluble forms-a result of regulated alternative splicing?" Biochimica et Biophysica Acta, vol. 1630, no. 1, pp. 1-6, 2003.

[82] M. Andrassy, H. C. Volz, J. C. Igwe et al., "High-mobility group box-1 in ischemia-reperfusion injury of the heart," Circulation, vol. 117, no. 25, pp. 3216-3226, 2008.

[83] Z. A. Ibrahim, C. L. Armour, S. Phipps, and M. B. Sukkar, "RAGE and TLRs: relatives, friends or neighbours?" Molecular Immunology, vol. 56, pp. 739-744, 2013.

[84] F. G. Bauernfeind, G. Horvath, A. Stutz et al., "Cutting edge: NF- $\kappa \mathrm{B}$ activating pattern recognition and cytokine receptors license NLRP3 inflammasome activation by regulating NLRP3 expression," The Journal of Immunology, vol. 183, no. 2, pp. 787791, 2009.

[85] K. Schroder, V. Sagulenko, A. Zamoshnikova et al., "Acute lipopolysaccharide priming boosts inflammasome activation independently of inflammasome sensor induction," Immunobiology, vol. 217, pp. 1325-1329, 2012.
[86] Y. Qiao, P. Wang, J. Qi, L. Zhang, and C. Gao, “TLR-induced NF- $\kappa$ B activation regulates NLRP3 expression in murine macrophages," FEBS Letters, vol. 586, no. 7, pp. 1022-1026, 2012.

[87] B. C. Mercier, E. Ventre, M. -L. Fogeron et al., "NOD1 cooperates with TLR2 to enhance T cell receptor-mediated activation in CD8 T cells," PLoS ONE, vol. 7, Article ID e42170, 2012.

[88] G. Jiang, D. Sun, H. J. Kaplan, and H. Shao, "Retinal astrocytes pretreated with NOD2 and TLR2 ligands activate uveitogenic T cells," PLoS ONE, vol. 7, Article ID e40510, 2012.

[89] T. Watanabe, A. Kitani, P. J. Murray, and W. Strober, "NOD2 is a negative regulator of Toll-like receptor 2-mediated Thelper type 1 responses," Nature Immunology, vol. 5, no. 8, pp. 800-808, 2004.

[90] H. S. Hreggvidsdottir, T. Östberg, H. Wähämaa et al., “The alarmin HMGB1 acts in synergy with endogenous and exogenous danger signals to promote inflammation," Journal of Leukocyte Biology, vol. 86, no. 3, pp. 655-662, 2009.

[91] J. H. Youn, Y. J. Oh, E. S. Kim, J. E. Choi, and J.-S. Shin, "High mobility group box 1 protein binding to lipopolysaccharide facilitates transfer of lipopolysaccharide to CD14 and enhances lipopolysaccharide-mediated TNF- $\alpha$ production in human monocytes," The Journal of Immunology, vol. 180, no. 7, pp. 5067-5074, 2008.

[92] J. Tian, A. M. Avalos, S.-Y. Mao et al., “Toll-like receptor 9dependent activation by DNA-containing immune complexes is mediated by HMGB1 and RAGE," Nature Immunology, vol. 8, no. 5, pp. 487-496, 2007.

[93] A. Tsung, R. Sahai, H. Tanaka et al., "The nuclear factor HMGB1 mediates hepatic injury after murine liver ischemiareperfusion," Journal of Experimental Medicine, vol. 201, no. 7, pp. 1135-1143, 2005.

[94] J. Qiu, M. Nishimura, Y. Wang et al., "Early release of HMGB1 from neurons after the onset of brain ischemia," Journal of Cerebral Blood Flow and Metabolism, vol. 28, no. 5, pp. 927-938, 2008.

[95] T. Kohno, T. Anzai, K. Naito et al., "Role of high-mobility group box 1 protein in post-infarction healing process and left ventricular remodelling," Cardiovascular Research, vol. 81, no. 3, pp. 565-573, 2009.

[96] R. S. Goldstein, M. Gallowitsch-Puerta, L. Yang et al., "Elevated high-mobility group box 1 levels in patients with cerebral and myocardial ischemia," Shock, vol. 25, no. 6, pp. 571-574, 2006.

[97] F. Giallauria, P. Cirillo, R. Lucci et al., "Autonomic dysfunction is associated with high mobility group box-1 levels in patients after acute myocardial infarction," Atherosclerosis, vol. 208, no. 1, pp. 280-284, 2010.

[98] P. Cirillo, F. Giallauria, M. Pacileo et al., "Increased high mobility group box-1 protein levels are associated with impaired cardiopulmonary and echocardiographic findings after acute myocardial infarction," Journal of Cardiac Failure, vol. 15, no. 4, pp. 362-367, 2009.

[99] K. Takahashi, S. Fukushima, K. Yamahara et al., "Modulated inflammation by injection of high-mobility group box 1 recovers post-infarction chronically failing heart," Circulation, vol. 118, no. 14, pp. S106-S114, 2008.

[100] Y.-Y. He, Y. Wen, X.-X. Zheng, and X.-J. Jiang, "Intramyocardial delivery of HMGB1 by a novel thermosensitive hydrogel attenuates cardiac remodeling and improves cardiac function after myocardial infarction," Journal of Cardiovascular Pharmacology, vol. 61, pp. 283-290, 2013.

[101] F. Limana, A. Germani, A. Zacheo et al., "Exogenous highmobility group box 1 protein induces myocardial regeneration 
after infarction via enhanced cardiac C-kit+ cell proliferation and differentiation," Circulation Research, vol. 97, no. 8, pp. e73e83, 2005.

[102] T. Kitahara, Y. Takeishi, M. Harada et al., "High-mobility group box 1 restores cardiac function after myocardial infarction in transgenic mice," Cardiovascular Research, vol. 80, no. 1, pp. 4046, 2008.

[103] Y. J. Woo, M. D. Taylor, J. E. Cohen et al., "Ethyl pyruvate preserves cardiac function and attenuates oxidative injury after prolonged myocardial ischemia," Journal of Thoracic and Cardiovascular Surgery, vol. 127, no. 5, pp. 1262-1269, 2004.

[104] X. Hu, H. Jiang, B. Cui, C. Xu, Z. Lu, and B. He, "Preconditioning with high mobility group box 1 protein protects against myocardial ischemia-reperfusion injury," International Journal of Cardiology, vol. 145, no. 1, pp. 111-112, 2010.

[105] S. Vandervelde, M. J. van Amerongen, R. A. Tio, A. H. Petersen, M. J. A. van Luyn, and M. C. Harmsen, "Increased inflammatory response and neovascularization in reperfused versus nonreperfused murine myocardial infarction," Cardiovascular Pathology, vol. 15, no. 2, pp. 83-90, 2006.

[106] M. T. Lotze and K. J. Tracey, "High-mobility group box 1 protein (HMGB1): nuclear weapon in the immune arsenal," Nature Reviews Immunology, vol. 5, no. 4, pp. 331-342, 2005.

[107] K. Tanonaka, H. Yoshida, W. Toga, K.-I. Furuhama, and S. Takeo, "Myocardial heat shock proteins during the development of heart failure," Biochemical and Biophysical Research Communications, vol. 283, no. 2, pp. 520-525, 2001.

[108] K. Tanonaka, W. Toga, H. Yoshida, and S. Takeo, "Myocardial heat shock protein changes in the failing heart following coronary artery ligation," Heart Lung and Circulation, vol. 12, no. 1, pp. 60-65, 2003.

[109] A. A. Knowlton, S. Kapadia, G. Torre-Amione et al., "Differential expression of heat shock proteins in normal and failing human hearts," Journal of Molecular and Cellular Cardiology, vol. 30, no. 4, pp. 811-818, 1998.

[110] Z. Li, Y. Song, R. Xing et al., "Heat shock protein 70 acts as a potential biomarker for early diagnosis of heart failure," PLoS ONE, vol. 8, Article ID e67964, 2013.

[111] B. Dybdahl, S. A. Slørdahl, A. Waage, P. Kierulf, T. Espevik, and A. Sundan, "Myocardial ischaemia and the inflammatory response: release of heat shock protein 70 after myocardial infarction," Heart, vol. 91, no. 3, pp. 299-304, 2005.

[112] B. Zal, J. C. Kaski, G. Arno et al., "Heat-shock protein 60reactive $\mathrm{CD} 4+\mathrm{CD} 28$ null $\mathrm{T}$ cells in patients with acute coronary syndromes," Circulation, vol. 109, no. 10, pp. 1230-1235, 2004.

[113] A. Asea, S.-K. Kraeft, E. A. Kurt-Jones et al., "HSP70 stimulates cytokine production through a CD 14-dependant pathway, demonstrating its dual role as a chaperone and cytokine," Nature Medicine, vol. 6, no. 4, pp. 435-442, 2000.

[114] N. L. Lubbers, J. S. Polakowski, C. D. Wegner et al., "Oral bimoclomol elevates heat shock protein 70 and reduces myocardial infarct size in rats," European Journal of Pharmacology, vol. 435, no. 1, pp. 79-83, 2002.

[115] D. S. Pisetsky, "The origin and properties of extracellular DNA: from PAMP to DAMP," Clinical Immunology, vol. 144, no. 1, pp. 32-40, 2012.

[116] Q. Zhang, M. Raoof, Y. Chen et al., "Circulating mitochondrial DAMPs cause inflammatory responses to injury," Nature, vol. 464, no. 7285, pp. 104-107, 2010.

[117] T. Oka, S. Hikoso, O. Yamaguchi et al., "Mitochondrial DNA that escapes from autophagy causes inflammation and heart failure," Nature, vol. 485, pp. 251-255, 2012.
[118] K. Konstantinidis and R. Kitsis, "Escaped DNA inflames the heart," Nature, vol. 485, pp. 179-180, 2012.

[119] M. Bliksøen, L. H. Mariero, I. K. Ohm et al., "Increased circulating mitochondrial DNA after myocardial infarction," International Journal of Cardiology, vol. 158, pp. 132-134, 2012.

[120] Y.-F. Liao, P. J. Gotwals, V. E. Koteliansky, D. Sheppard, and L. D. Van Water, "The EIIIA segment of fibronectin is a ligand for integrins $\alpha 9 \beta 1$ and $\alpha 9 \beta 1$ providing a novel mechanism for regulating cell adhesion by alternative splicing," The Journal of Biological Chemistry, vol. 277, no. 17, pp. 14467-14474, 2002.

[121] F. Arslan, M. B. Smeets, P. W. Riem Vis et al., "Lack of fibronectin-EDA promotes survival and prevents adverse remodeling and heart function deterioration after myocardial infarction," Circulation Research, vol. 108, no. 5, pp. 582-592, 2011.

[122] N. G. Frangogiannis, "Matricellular proteins in cardiac adaptation and disease," Physiological Reviews, vol. 92, no. 2, pp. 635688, 2012.

[123] Y. Zhao, S. L. Young, and J. C. McIntosh, "Induction of tenascin in rat lungs undergoing bleomycin-induced pulmonary fibrosis," The American Journal of Physiology: Lung Cellular and Molecular Physiology, vol. 274, no. 6, pp. L1049-L1057, 1998.

[124] A. Sato, M. Hiroe, D. Akiyama et al., "Prognostic value of serum tenascin-C levels on long-term outcome after acute myocardial infarction," Journal of Cardiac Failure, vol. 18, no. 6, pp. 480486, 2012.

[125] A. Sato, K. Aonuma, K. Imanaka-Yoshida et al., "Serum tenascin-C might be a novel predictor of left ventricular remodeling and prognosis after acute myocardial infarction," Journal of the American College of Cardiology, vol. 47, no. 11, pp. 2319-2325, 2006.

[126] T. Nishioka, K. Onishi, N. Shimojo et al., "Tenascin-C may aggravate left ventricular remodeling and function after myocardial infarction in mice," The American Journal of Physiology: Heart and Circulatory Physiology, vol. 298, no. 3, pp. H1072H1078, 2010.

[127] I. E. Willems, J. W. Arends, and M. J. Daemen, “Tenascin and fibronectin expression in healing human myocardial scars," The Journal of Pathology, vol. 179, pp. 321-325, 1996.

[128] R. A. Clark, H. P. Erickson, and T. A. Springer, "Tenascin supports lymphocyte rolling," Journal of Cell Biology, vol. 137, no. 3, pp. 755-765, 1997.

[129] C. R. Ruegg, R. Chiquet-Ehrismann, and S. S. Alkan, “Tenascin, an extracellular matrix protein, exerts immunomodulatory activities," Proceedings of the National Academy of Sciences of the United States of America, vol. 86, no. 19, pp. 7437-7441, 1989.

[130] T. J. Hemesath, L. S. Marton, and K. Stefansson, "Inhibition of T cell activation by the extracellular matrix protein tenascin," The Journal of Immunology, vol. 152, no. 11, pp. 5199-5207, 1994.

[131] J. D. Loike, L. Cao, S. Budhu, S. Hoffman, and S. C. Silverstein, "Blockade of $\alpha 5 \beta 1$ integrins reverses the inhibitory effect of tenascin on chemotaxis of human monocytes and polymorphonuclear leukocytes through three-dimensional gels of extracellular matrix proteins," The Journal of Immunology, vol. 166, no. 12, pp. 7534-7542, 2001.

[132] C. E. Murry, C. M. Giachelli, S. M. Schwartz, and R. Vracko, "Macrophages express osteopontin during repair of myocardial necrosis," The American Journal of Pathology, vol. 145, no. 6, pp. 1450-1462, 1994.

[133] K. X. Wang and D. T. Denhardt, "Osteopontin: role in immune regulation and stress responses," Cytokine and Growth Factor Reviews, vol. 19, no. 5-6, pp. 333-345, 2008. 
[134] B. Zhu, K. Suzuki, H. A. Goldberg et al., "Osteopontin modulates CD44-dependent chemotaxis of peritoneal macrophages through G-protein-coupled receptors: evidence of a role for an intracellular form of osteopontin," Journal of Cellular Physiology, vol. 198, no. 1, pp. 155-167, 2004.

[135] E. E. Rollo and D. T. Denhardt, "Differential effects of osteopontin on the cytotoxic activity of macrophages from young and old mice," Immunology, vol. 88, no. 4, pp. 642-647, 1996.

[136] Y. Koguchi, K. Kawakami, S. Kon et al., "Penicillium marneffei causes osteopontin-mediated production of interleukin-12 by peripheral blood mononuclear cells," Infection and Immunity, vol. 70, no. 3, pp. 1042-1048, 2002.

[137] S. A. Vetrone, E. Montecino-Rodriguez, E. Kudryashova et al., "Osteopontin promotes fibrosis in dystrophic mouse muscle by modulating immune cell subsets and intramuscular TGF- $\beta$," Journal of Clinical Investigation, vol. 119, no. 6, pp. 1583-1594, 2009.

[138] S. Ashkar, G. F. Weber, V. Panoutsakopoulou et al., "Eta-1 (osteopontin): an early component of type-1 (cell-mediated) immunity," Science, vol. 287, no. 5454, pp. 860-864, 2000.

[139] K. Kawamura, K. Iyonaga, H. Ichiyasu, J. Nagano, M. Suga, and Y. Sasaki, "Differentiation, maturation, and survival of dendritic cells by osteopontin regulation," Clinical and Diagnostic Laboratory Immunology, vol. 12, no. 1, pp. 206-212, 2005.

[140] A. C. Renkl, J. Wussler, T. Ahrens et al., "Osteopontin functionally activates dendritic cells and induces their differentiation toward a Thl-polarizing phenotype," Blood, vol. 106, no. 3, pp. 946-955, 2005.

[141] N. A. Trueblood, Z. Xie, C. Communal et al., "Exaggerated left ventricular dilation and reduced collagen deposition after myocardial infarction in mice lacking osteopontin," Circulation Research, vol. 88, no. 10, pp. 1080-1087, 2001.

[142] M. Dobaczewski, M. Bujak, P. Zymek, G. Ren, M. L. Entman, and N. G. Frangogiannis, "Extracellular matrix remodeling in canine and mouse myocardial infarcts," Cell and Tissue Research, vol. 324, no. 3, pp. 475-488, 2006.

[143] I. Komatsubara, T. Murakami, S. Kusachi et al., "Spatially and temporally different expression of osteonectin and osteopontin in the infarct zone of experimentally induced myocardial infarction in rats," Cardiovascular Pathology, vol. 12, no. 4, pp. 186-194, 2003.

[144] P. Kossmehl, J. Schönberger, M. Shakibaei et al., "Increase of fibronectin and osteopontin in porcine hearts following ischemia and reperfusion," Journal of Molecular Medicine, vol. 83, no. 8, pp. 626-637, 2005.

[145] C. Suezawa, S. Kusachi, T. Murakami et al., "Time-dependent changes in plasma osteopontin levels in patients with anteriorwall acute myocardial infarction after successful reperfusion: correlation with left-ventricular volume and function," Journal of Laboratory and Clinical Medicine, vol. 145, no. 1, pp. 33-40, 2005.

[146] M. Scatena, L. Liaw, and C. M. Giachelli, "Osteopontin: a multifunctional molecule regulating chronic inflammation and vascular disease," Arteriosclerosis, Thrombosis, and Vascular Biology, vol. 27, no. 11, pp. 2302-2309, 2007.

[147] P. Hsu, B. Su, Q. -Y. Kuok, and F. Mo, "Extracellular matrix protein $\mathrm{CCN} 1$ regulates cardiomyocyte apoptosis in mice with stress-induced cardiac injury," Cardiovascular Research, vol. 98, pp. 64-72, 2013.

[148] D. Hilfiker-Kleiner, K. Kaminski, A. Kaminska et al., "Regulation of proangiogenic factor $\mathrm{CCN} 1$ in cardiac muscle: impact of ischemia, pressure overload, an neurohumoral activation," Circulation, vol. 109, no. 18, pp. 2227-2233, 2004.

[149] T. Bai, C.-C. Chen, and L. F. Lau, "Matricellular protein $\mathrm{CCN1}$ activates a proinflammatory genetic program in murine macrophages," The Journal of Immunology, vol. 184, no. 6, pp. 3223-3232, 2010.

[150] M. Rother, S. Krohn, G. Kania et al., "Matricellular signaling molecule CCN1 attenuates experimental autoimmune myocarditis by acting as a novel immune cell migration modulator," Circulation, vol. 122, no. 25, pp. 2688-2698, 2010.

[151] M. Löbel, S. Bauer, C. Meisel et al., "CCN1: a novel inflammation-regulated biphasic immune cell migration modulator," Cellular and Molecular Life Sciences, vol. 69, no. 18, pp. 3101-3113, 2012.

[152] M. T. Elola, C. Wolfenstein-Todel, M. F. Troncoso, G. R. Vasta, and G. A. Rabinovich, "Galectins: matricellular glycan-binding proteins linking cell adhesion, migration, and survival," Cellular and Molecular Life Sciences, vol. 64, no. 13, pp. 1679-1700, 2007.

[153] S. Sato, C. St-Pierre, P. Bhaumik, and J. Nieminen, "Galectins in innate immunity: dual functions of host soluble $\beta$ galactoside-binding lectins as damage-associated molecular patterns (DAMPs) and as receptors for pathogen-associated molecular patterns (PAMPs)," Immunological Reviews, vol. 230, no. 1, pp. 172-187, 2009.

[154] R. A. P. Weir, C. J. Petrie, C. A. Murphy et al., "Galectin-3 and cardiac function in survivors of acute myocardial infarction," Circulation, vol. 6, pp. 492-498, 2013.

[155] I. M. Seropian, J. P. Cerliani, S. Toldo, B. W. van Tassell et al., "Galectin-1 controls cardiac inflammation and ventricular remodeling during acute myocardial infarction," The American Journal of Pathology, vol. 182, pp. 29-40, 2013.

[156] H. Sano, D. K. Hsu, L. Yu et al., "Human galectin-3 is a novel chemoattractant for monocytes and macrophages," The Journal of Immunology, vol. 165, no. 4, pp. 2156-2164, 2000.

[157] J. A. Fulcher, S. T. Hashimi, E. L. Levroney et al., "Galectin1-matured human monocyte-derived dendritic cells have enhanced migration through extracellular matrix," The Journal of Immunology, vol. 177, no. 1, pp. 216-226, 2006.

[158] M. V. Sørensen, S. Pedersen, R. Møgelvang, J. Skov-Jensen, and A. Flyvbjerg, "Plasma high-mobility group box 1 levels predict mortality after ST-segment elevation myocardial infarction," JACC, vol. 4, no. 3, pp. 281-286, 2011.

[159] T. Hashimoto, J. Ishii, F. Kitagawa et al., "Circulating highmobility group box 1 and cardiovascular mortality in unstable angina and non-ST-segment elevation myocardial infarction," Atherosclerosis, vol. 221, no. 2, pp. 490-495, 2012.

[160] J. H. Peters, M. N. Grote, N. E. Lane, and R. J. Maunder, "Changes in plasma fibronectin isoform levels predict distinct clinical outcomes in critically III patients," Biomarker Insights, vol. 6, pp. 59-68, 2011. 


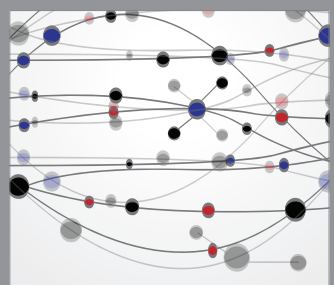

The Scientific World Journal
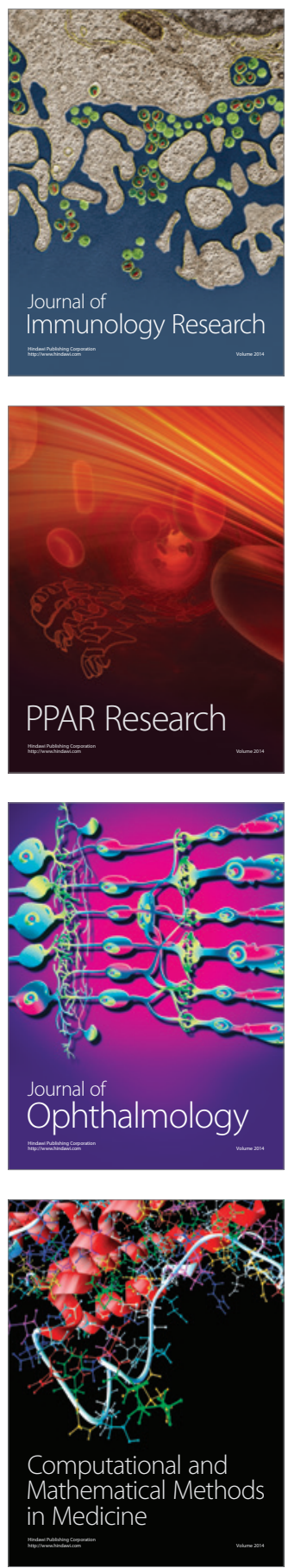

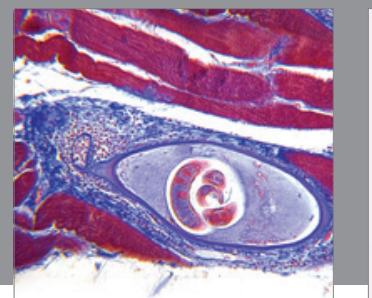

Gastroenterology

Research and Practice
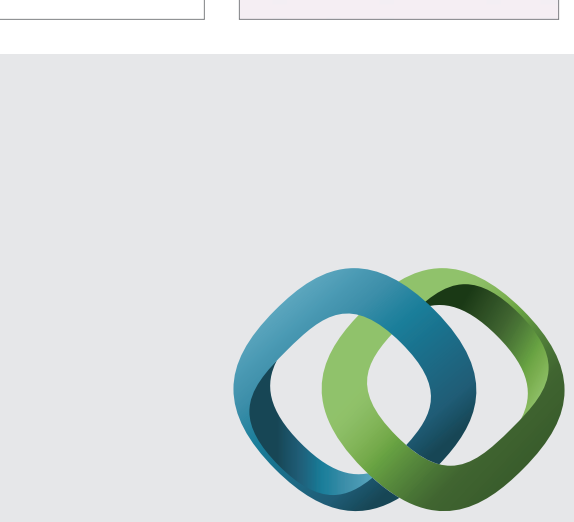

\section{Hindawi}

Submit your manuscripts at

http://www.hindawi.com
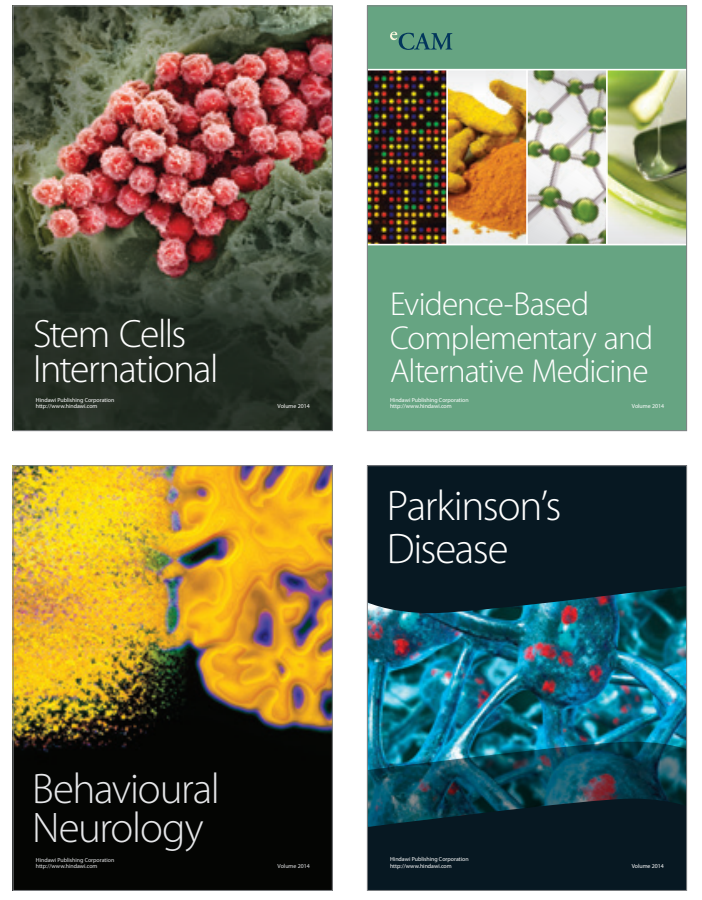
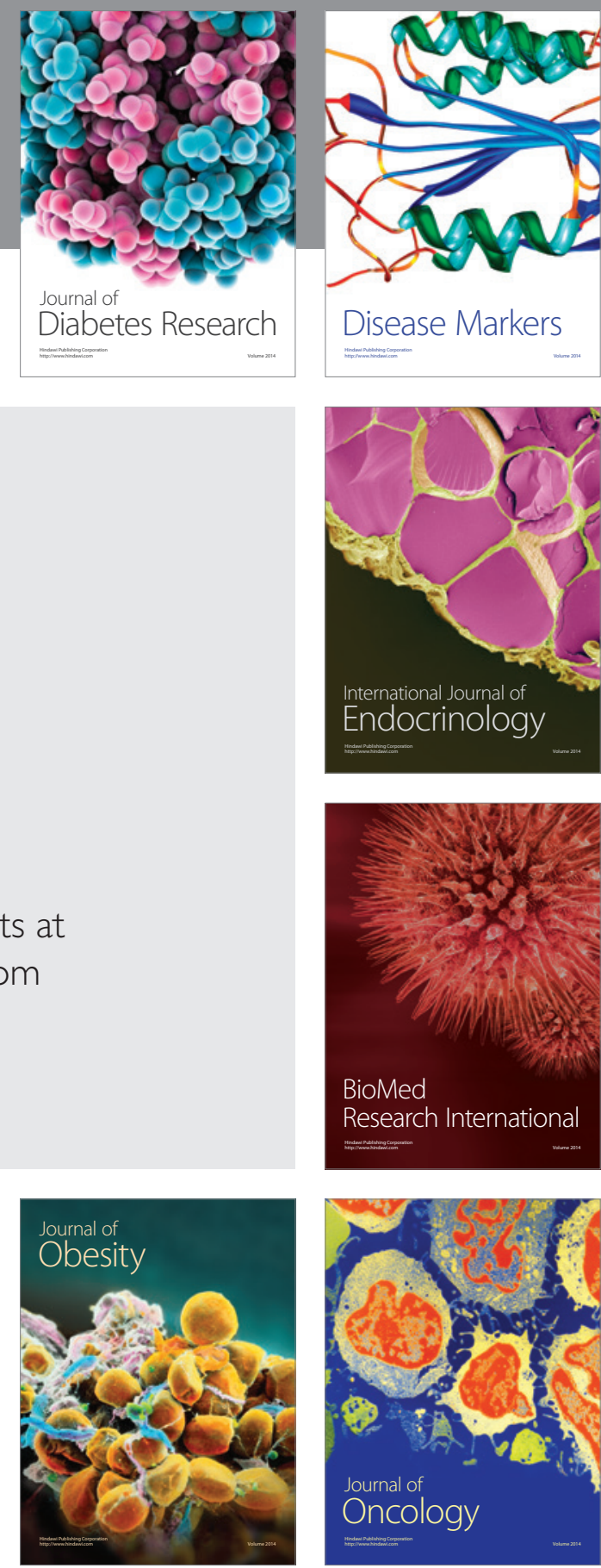

Disease Markers
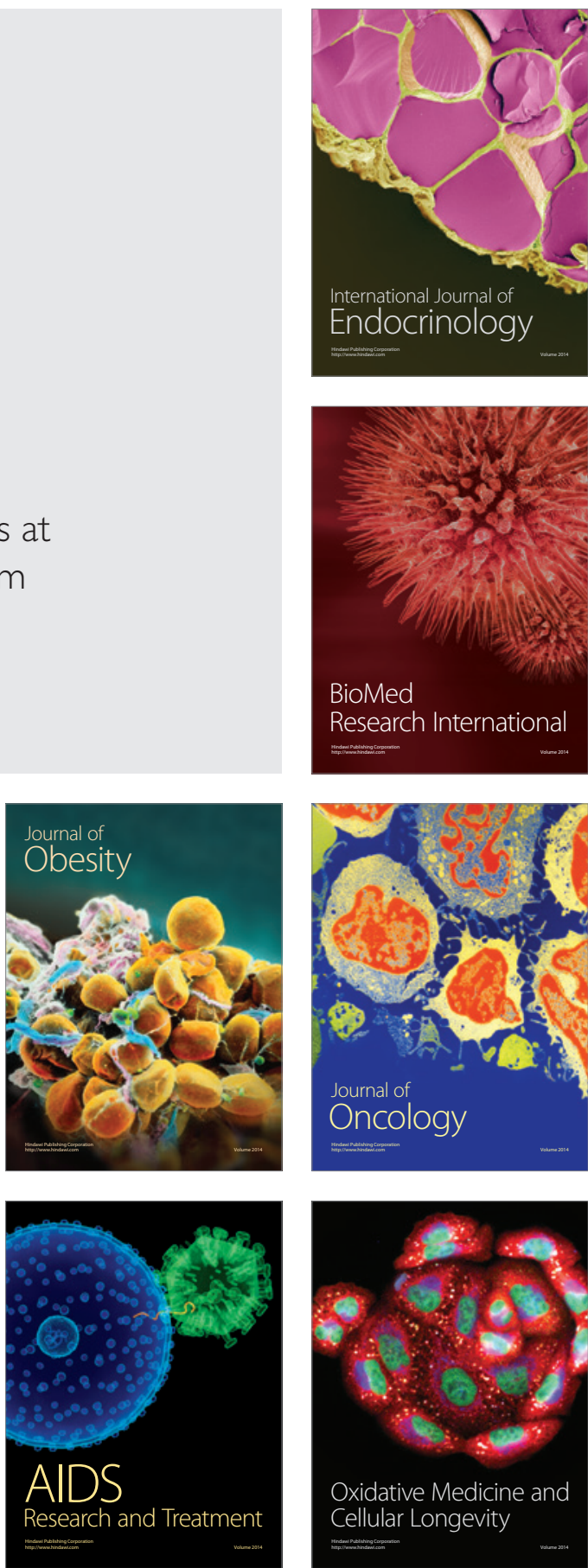